\title{
Axonal dysfunction in the neuropathy of diabetes mellitus: a quantitative electrophysiological study
}

\author{
ST I G H N S N A N D JOH N P. BALLANT Y NE \\ From the University Department of Neurology, Institute of Neurological Sciences, \\ Southern General Hospital, Glasgow
}

SUMMARY The extent of axonal dysfunction in a group of patients with diabetes mellitus has been investigated using recently introduced quantitative techniques of electromyography. In 40 diabetic patients, estimates of motor unit numbers in the extensor digitorum brevis muscles and measurements of the parameters of electrically evoked motor unit potentials therein are presented, along with significant correlations between these parameters and motor nerve conduction velocities and distal motor latencies in the lateral popliteal nerves. The results indicate that axonal dysfunction and concomitant collateral reinnervation are prominent and integral features of the neuropathy of diabetes mellitus. Axonal dysfunction is present in proportion to and parallels the severity of the demyelinative lesion. It is also extensive in patients without clinical evidence of neuropathy in whom the accompanying collateral reinnervation is of sufficient magnitude to mask the clinical signs of motor involvement.

There are many reports in the literature on the electrophysiological abnormalities in the peripheral nerves of patients with diabetes mellitus (Gilliatt et al., 1961; Mulder et al., 1961; Gilliatt and Willison, 1962; Gregersen, 1967; Lamontagne and Buchthal, 1970). These studies have been confined largely to attempts to correlate the clinical manifestations and/or histopathological appearances with slowing of conduction in motor and sensory nerve fibres or both, in some cases supplemented by needle EMG studies. The electrophysiological methods used have provided some quantitative data on the sensory nerve function but only qualitative information on the pathophysiological changes in the peripheral motor nerves.

Histopathological studies have indicated that the predominant abnormality in diabetic neuropathy is segmental demyelination and remyelination (Thomas and Lascelles, 1966; Chopra et al., 1969), although Dolman (1963) found evidence of axonal loss and the changes of neurogenic atrophy in some muscle biopsies. Electrophysiological studies have also provided some evidence of axonal dysfunction in the form of fibrillation potentials and reduced EMG interference pattern to voluntary effort (Mulder et al., 1961; Lamontagne and
Buchthal, 1970). Brown and Feasby (1974) noted a reduction in motor unit numbers in some of their patients but were unable to indicate the relative roles of axonal dysfunction and demyelinative block in producing these changes. That a disturbance of axonal function is present in some patients with diabetic neuropathy is not, therefore, in doubt. Since, however, quantitative electrophysiological information has not hitherto been available, the relative importance of axonal dysfunction in the pathogenesis and evolution of the neuropathy has not been elucidated.

The purpose of the present paper is to report the results of the application of a quantitative method for the estimation of motor unit numbers in the extensor digitorum brevis (EDB) muscles of a group of diabetic patients, together with the changes in the measurable parameters of electrically evoked motor unit potentials from the same muscle obtained by a computer subtraction method (Ballantyne and Hansen, 1974a, b).

The relative roles of axonal dysfunction and segmental demyelination in diabetes mellitus are discussed in the light of motor unit estimations, motor nerve conduction velocities, and the quantitative changes in the motor unit potential parameters in patients with and without clinical evidence of neuropathy. 


\section{Methods}

The composition and placement of the surface recording electrodes over the EDB muscle, the properties of the stimulating electrodes over the anterior tibial nerve at the ankle, and the details of the rate and strength of stimulation used to evoke motor unit potentials have been described previously (Ballantyne and Hansen, 1974a). The amplification and display systems, the computer handling of data for the estimation of motor unit numbers in the EDB muscle, and the computer derivation of the parameters of electrically evoked motor unit potentials have also been reported (Ballantyne and Hansen, 1974a, b).

Briefly, motor unit potentials (MUPs) recorded from surface electrodes over the EDB muscle are evoked sequentially by finely graded incremental stimulation of the anterior tibial nerve at the ankle. Up to 15 motor unit potential increments can be recognised by a combination of visual and computer analysis of the muscle action potential. The first MUP is displayed in isolation on the oscilloscope screen, the second is contained in a compound potential containing MUPs one and two, the third is contained in a compound potential containing MUPs one, two, and three, and so on. As each new potential is added to the preceding one the compound potential so constituted is stored in a computer memory (template). Template 1 contains MUP 1 , template 2 contains MUPs 1 and 2, template 3, MUPs 1, 2, and 3, and so on. Up to 15 templates can be stored. The number of motor units in the EDB muscle is calculated from the formula:

$$
\mathrm{MUC}=\mathrm{n}\left(\frac{\mathrm{A}(\mathrm{M})}{\mathrm{A}(\mathrm{n})}\right)
$$

where $\mathbf{A}(\mathbf{M})=$ area of supramaximally evoked muscle action potential

$A(n)=$ area of the compound muscle action potential containing $\mathrm{n}$ MUPs (Ballantyne and Hansen, 1974a).

By a process of template subtraction the computer also displays the first $\mathrm{n}$ sequentially recruited MUPs in isolation. For example, subtraction of template 1 from template 2 will display MUP 2, subtraction of template 3 from 4 will leave MUP 3 in isolation, and so on. The latencies, durations, amplitudes, and areas of the MUPs are then measured. Amplitudes and areas are provided by the computer while latencies and durations are measured manually from a computer printout (Ballantyne and Hansen, 1974b). In order to avoid confusion with other reports in the literature, however, it is important to emphasise that all recordings in these studies were from surface electrodes over the EDB muscle.

Fastest motor nerve conduction velocities (FMNCV) in the lateral popliteal nerve (knee to ankle segment) and shortest distal motor latencies (SDML) (anterior tibial nerve at the ankle to the EDB muscle) were also measured from the same surface electrodes over the EDB muscle. All investigations were undertaken in a thermostatically controlled room and limb temperature maintained at $33^{\circ} \mathrm{C} \pm 1{ }^{\circ} \mathrm{C}$.

PATIENTS WITH DIABETES MELLITUS

(All values are expressed as the mean \pm one standard deviation.)

Forty patients with diabetes mellitus aged 48.6士 11.3 years attending the diabetic clinic at the Southern General Hospital, Glasgow, agreed to take part in the study. All patients were examined by one of us (JPB) and, since our investigations have involved the lateral popliteal nerve and EDB muscle, particular attention was paid to the presence of clinical evidence of neuropathy affecting the legs. The patients included in the neuropathic group had one of the following symptoms and/or signs; symmetrical subjective sensory disturbance in the legs, usually paraesthesia and/or numbness of the feet; objective symmetrical sensory disturbance in the form of reduction in vibration sense or reduction in other modalities of sensation in a symmetrical distribution in the legs; a reduction or absence of tendon reflexes at the knee and/or ankles and the presence of symmetrical distal weakness in the legs. No attempt was made to grade the severity of the clinical neuropathy; patients who were thought to have a mononeuritis affecting the lateral popliteal nerve were excluded from the study, but not those with mononeuritides of the upper limbs or other evidence of diabetic neuropathy such as diabetic amyotrophy, provided they also had additional evidence of neuropathy as above. The patients included in the non-neuropathic group had no clinical evidence of a generalised neuropathy nor of a mononeuritis or a mononeuritis multiplex.

Thirteen of the patients (aged $48.5 \pm 10.1$ years) fell into the neuropathic group. The remaining 27 patients aged $48.6 \pm 12.1$ years were completely free of symptoms of neuropathy. The duration of diabetes in the group as a whole was 9.0 \pm 8.9 years. In the 27 patients without clinical neuropathy the duration of diabetes was $7.7 \pm 7.4$ years (range two months-28 years), and in the symptomatic group of thirteen patients $11.7 \pm 11.2$ years 
(range two months-37 years). There was no evidence in any of these patients of any other condition which would give rise to a peripheral neuropathy.

Of the 40 patients with diabetes mellitus, 19 were on treatment with insulin and 21 were on treatment with diet and oral hypoglycaemic agents or both. Of the 27 patients without evidence of clinical neuropathy, 10 were on treatment with insulin, while in the group of 13 patients with neuropathy, nine were on treatment with insulin.

\section{CONTROL SUBJECTS}

There were 27 control subjects aged $46.9 \pm 12.4$ years drawn from the staff of the Institute of Neurological Sciences, Southern General Hospital, Glasgow, and their relatives. The oldest control subjects were a group of elderly ambulant pensioners attending a local authority day centre.
All control subjects were without neurological disease.

\section{Results}

All results are expressed as the mean \pm 1 SD. Statistical significance of the difference between mean values have been assessed using Student's $t$ test.

AGE OF PATIENTS

There was no significant difference between the ages of the 27 patients without evidence of neuropathy and the 13 patients with neuropathy (Table 1).

\section{DURATION OF DIABETES}

While the duration of diabetes in the symptomatic patients was lower than in the asymptomatic group

Table 1 Mean ages and electrophysiological parameters: control subjects and patients with diabetes mellitus

\begin{tabular}{|c|c|c|c|c|c|}
\hline & \multirow[t]{2}{*}{ Number in group } & \multirow[t]{2}{*}{ Mean } & \multirow[t]{2}{*}{$S D$} & \multicolumn{2}{|c|}{$\mathbf{P}$} \\
\hline & & & & with controls & between groups \\
\hline \multicolumn{6}{|l|}{ Age (yr) } \\
\hline Control & 27 & 46.9 & 12.4 & - & \multirow{6}{*}{$\begin{array}{l}\text { NS } \\
<0.005\end{array}$} \\
\hline All & 40 & 48.6 & 11.3 & NS & \\
\hline Non-N & 27 & 48.6 & 12.1 & NS & \\
\hline N & 13 & 48.5 & 10.1 & NS & \\
\hline D & 21 & 53.7 & 6.0 & $<0.02$ & \\
\hline I & 19 & 42.9 & 13.2 & NS & \\
\hline \multicolumn{6}{|c|}{ Duration of diabetes (yr) } \\
\hline Control & - & - & - & - & \multirow[b]{6}{*}{$<0.001$} \\
\hline All & 39 & 9.0 & 8.9 & - & \\
\hline Non- $\mathrm{N}$ & 26 & 7.7 & 7.4 & - & \\
\hline $\mathbf{N}$ & 13 & 11.7 & 11.2 & - & \\
\hline D & 20 & 4.2 & 4.0 & - & \\
\hline I & 19 & 14.2 & 9.8 & - & \\
\hline \multicolumn{6}{|c|}{ Shortest distal motor latency (ms) } \\
\hline Control & 27 & 3.56 & 0.45 & - & \multirow{6}{*}{ NS } \\
\hline All & 40 & 4.56 & 0.99 & $<0.0002$ & \\
\hline Non-N & 27 & 4.38 & 0.94 & $<0.0005$ & \\
\hline $\mathrm{N}$ & 13 & 4.94 & 1.04 & $<0.001$ & \\
\hline D & 21 & 4.44 & 1.00 & $<0.002$ & \\
\hline $\mathbf{I}$ & 19 & 4.70 & 0.99 & $<0.0005$ & \\
\hline \multicolumn{6}{|c|}{$\begin{array}{l}\text { Fastest motor nerve conduction } \\
\text { velocity }(\mathrm{m} / \mathrm{s})\end{array}$} \\
\hline Control & 16 & 50.5 & 4.59 & - & \multirow{6}{*}{$<0.002$} \\
\hline All & 40 & 42.2 & 6.46 & $<0.0001$ & \\
\hline Non-N & 27 & 44.4 & 5.81 & $<0.002$ & \\
\hline $\mathbf{N}$ & 13 & 37.5 & 5.32 & $<0.0001$ & \\
\hline D & 21 & 44.7 & 5.32 & $<0.002$ & \\
\hline I & 19 & 39.4 & 6.58 & $<0.0001$ & \\
\hline \multicolumn{6}{|c|}{ Motor unit numbers } \\
\hline Control & 26 & 196.2 & 54.3 & - & \multirow{6}{*}{$<0.02$} \\
\hline All & 35 & 106.0 & 70.0 & $<0.0001$ & \\
\hline Non-N & 22 & 125.3 & 76.2 & $<0.001$ & \\
\hline $\mathbf{N}$ & 13 & 73.5 & 43.7 & $<0.0001$ & \\
\hline D & 17 & 112.5 & 68.3 & $<0.0002$ & \\
\hline I & 18 & 99.9 & 73.1 & $<0.0001$ & \\
\hline
\end{tabular}

Non- $\mathrm{N}=$ patients without signs and/or symptoms of neuropathy.

$\mathbf{N}=$ patients with signs and/or symptoms of neuropathy.

$\mathrm{D}=$ patients on diet and/or oral hypoglycaemic agents.

$\mathrm{I}=$ patients on insulin. 
the difference was not statistically significant (Table 1).

\section{SHORTEST DISTAL MOTOR LATENCIES}

In the patients with evidence of neuropathy and in those without, shortest distal motor latencies (SDML) were significantly increased over control values (Table 1).

\section{FASTEST MOTOR NERVE CONDUCTION VELOCITIES}

Fastest motor nerve conduction velocities (FMNCV) in patients with and without neuropathy were significantly reduced compared to control values (Table 1). The FMNCV in patients with neuropathy, however, were significantly less than in the patients without neuropathic signs. In the group as a whole-that is, the 40 diabetic patients-there was a significant negative correlation between fastest motor nerve conduction velocities and the duration of diabetes $(r=-0.439$; $\mathbf{P}<0.01$ ). There was also a significant negative correlation between FMNCV and SDML in these patients $(\mathrm{r}=-0.455 ; \mathrm{P}<0.005)$.

\section{MOTOR UNIT NUMBERS}

The number of motor units estimated in the EDB muscles of the patients with and without evidence of neuropathy were both significantly reduced compared to control values (Table 1). Motor unit numbers in the patients with neuropathy were significantly less than the values obtained in those patients without evidence of neuropathy. In the diabetic group as a whole there was a significant negative correlation between motor unit numbers and the age of the patient, $(r=-0.500 ; \mathrm{P}<0.005)$. There was also a significant negative correlation between motor unit numbers and SDML $(r=$ $-0.590 ; \mathrm{P}<0.001$ ) (Fig. 1), and a significant positive correlation between motor unit numbers and FMNCV ( $r=0.564 ; \mathrm{P}<0.001)$ (Fig. 2). There was also a negative correlation between the logarithm of motor unit numbers and the duration of diabetes in the group as a whole $(r=-0.352 ; \mathrm{P}<0.05)$.

\section{MOTOR UNIT POTENTIAL LATENCIES}

The latencies of individual motor unit potentials (MUP) were significantly prolonged in patients with and without evidence of neuropathy (Table 2 ). While this was most marked in the symptomatic group of patients, the mean value was not significantly different from that in the asymptomatic group. There was a positive correlation between mean MUP latencies and mean MUP durations $(r=0.533 ; \mathrm{P}<0.002)$.

MOTOR UNIT POTENTIAL DURATIONS

Motor unit potential durations in the patients without signs or symptoms were not significantly different from control values (Table 2). In the symptomatic patients, however, the mean MUP durations were significantly prolonged compared to control values and the values in the asymptomatic patients. Significant negative correlations were present between mean MUP durations and FMNCVs $(r=-0.528 ; \quad P<0.002)$, and between mean MUP durations and motor unit numbers

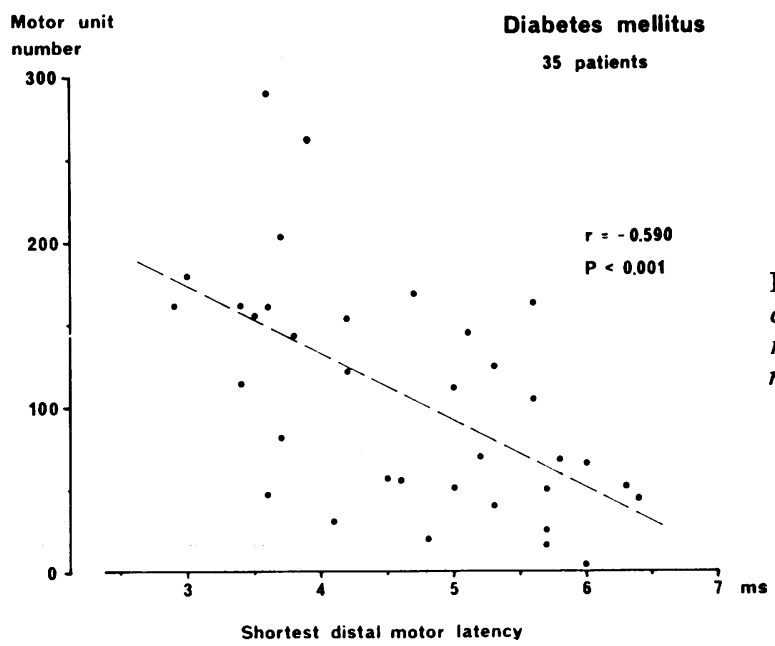

Fig. 1 Scattergram showing significant negative correlation between shortest distal motor latencies and motor unit numbers in group of patients with diabetes mellitus. 


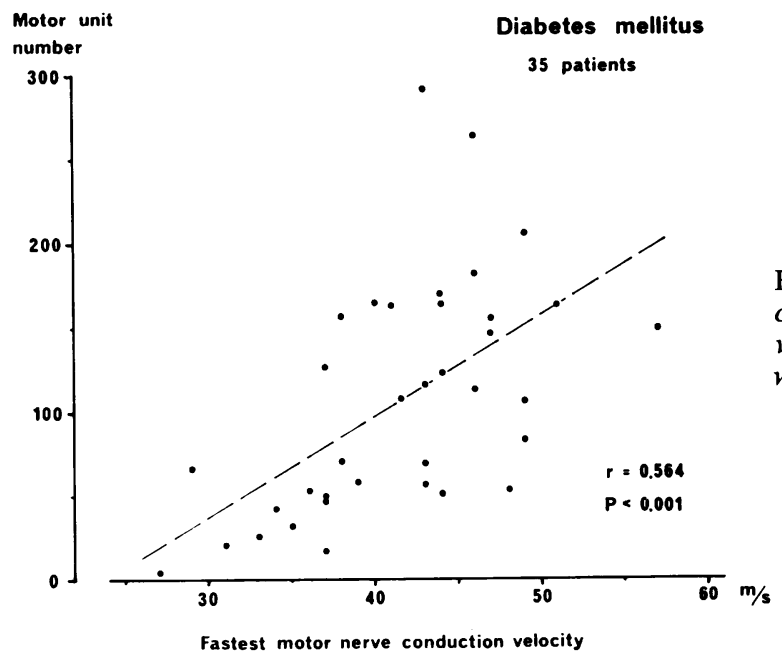

Fig. 2 Scattergram showing significant positive correlation between fastest motor nerve conduction velocities and motor unit numbers in group of patients with diabetes mellitus.

Table 2 Mean motor unit parameters in EDB muscles: control subjects and patients with diabetes mellitus

\begin{tabular}{|c|c|c|c|c|c|}
\hline & \multirow[t]{2}{*}{ Number in group } & \multirow[t]{2}{*}{ Mean } & \multirow[t]{2}{*}{$S D$} & \multicolumn{2}{|c|}{$\mathbf{P}$} \\
\hline & & & & with controls & between groups \\
\hline \multicolumn{6}{|c|}{ MUP latency (ms) } \\
\hline Control & 150 & 4.63 & 0.98 & - & \multirow{6}{*}{$\begin{array}{l}\text { NS } \\
\text { NS }\end{array}$} \\
\hline All & 270 & 5.70 & 1.55 & $<0.0001$ & \\
\hline Non-N & 192 & 5.70 & 1.61 & $<0.0001$ & \\
\hline $\mathbf{N}$ & 78 & 5.72 & 1.41 & $<0.0001$ & \\
\hline D & 150 & 5.72 & 1.67 & $<0.0001$ & \\
\hline I & 120 & 5.69 & 1.39 & $<0.0001$ & \\
\hline \multicolumn{6}{|c|}{ MUP duration (ms) } \\
\hline Control & 150 & 9.43 & 1.71 & - & \multirow{6}{*}{$\begin{array}{l}<0.0005 \\
\text { NS }\end{array}$} \\
\hline All & 270 & 9.66 & 1.99 & NS & \\
\hline Non-N & 192 & 9.36 & 1.87 & NS & \\
\hline $\mathbf{N}$ & 78 & 10.40 & 2.07 & $<0.001$ & \\
\hline D & 150 & 9.64 & 2.02 & NS & \\
\hline $\mathbf{I}$ & 120 & 9.68 & 1.95 & NS & \\
\hline \multicolumn{6}{|c|}{ MUP amplitude $(\mu \mathrm{V})$} \\
\hline Control & 150 & 61.9 & 30.1 & - & \multirow{6}{*}{$\begin{array}{l}<0.03 \\
\text { NS }\end{array}$} \\
\hline All & 270 & 109.5 & 127.9 & $<0.0001$ & \\
\hline Non-N & 192 & 117.6 & 146.5 & $<0.0001$ & \\
\hline $\mathbf{N}$ & 78 & 89.7 & 57.8 & $<0.0005$ & \\
\hline D & 150 & 97.3 & 110.7 & $<0.0005$ & \\
\hline $\mathbf{I}$ & 120 & 124.7 & 145.7 & $<0.0001$ & \\
\hline \multicolumn{6}{|c|}{ MUP area (area units) } \\
\hline Control & 150 & 17.4 & 8.4 & - & \multirow{6}{*}{ NS } \\
\hline All & 270 & 32.1 & 35.9 & $<0.0001$ & \\
\hline Non-N & 192 & 33.3 & 40.9 & $<0.0001$ & \\
\hline $\mathbf{N}$ & 78 & 29.3 & 18.2 & $<0.0001$ & \\
\hline D & 150 & 28.7 & 29.7 & $<0.0001\}$ & \\
\hline I & 120 & 36.4 & 42.1 & $<0.0001\}$ & \\
\hline
\end{tabular}

Non- $\mathrm{N}=$ patients without signs and/or symptoms of neuropathy.

$\mathrm{N}=$ patients with signs and/or symptoms of neuropathy.

$\mathbf{D}=$ patients on diet and/or oral hypoglycaemic agents.

$\mathbf{I}=$ patients on insulin.

$(\mathrm{r}=-0.543 ; \mathrm{P}<0.002)$. There was a significant positive correlation between mean MUP durations and SDMLs $(r=0.616 ; \mathrm{p}<0.001)$.
MOTOR UNIT POTENTIAL AMPLITUDES

Mean motor unit potential amplitudes were significantly increased in both groups of diabetic patients 
(Table 2). However, in the symptomatic group of patients, amplitudes were lower than those in the asymptomatic group although the difference was not statistically significant (see Discussion). There was a significant negative correlation between MUP amplitudes and motor unit numbers in the group as a whole $(\mathrm{r}=-0.386 ; \mathrm{P}<0.05)$.

\section{MOTOR UNIT POTENTIAL AREAS}

Mean motor unit potential areas were significantly increased in the diabetic group as a whole and in the two subgroups compared to control values (Table 2). There was no significant difference between the mean values in the symptomatic and asymptomatic patients. The whole group showed a significant positive correlation between mean MUP areas and SDML $(r=0.407 ; \mathrm{p}<0.02)$, and a significant negative correlation between mean MUP areas and motor unit numbers $(r=-0.459$; $\mathbf{P}<0.01$ ).

\section{PATIENTS ON INSULIN THERAPY}

The group of patients treated by diet and oral hypoglyaemic agents or both had a mean age significantly greater than the insulin treated group (Table 1). Mean motor unit numbers, shortest distal motor latencies, and MUP latencies, durations, amplitudes, and areas were not significantly different in the insulin treated compared to noninsulin treated patients, and not significantly different from the values in the diabetic group as a whole. However, fastest motor nerve conduction velocities were significantly lower in the insulin treated patients than in those receiving other forms of therapy (Table 1).

\section{Discussion}

The statistical significances of the correlations referred to in the text are shown in Table 3. Reports in the literature indicate that in the study of diabetic neuropathy, investigation of the extensor digitorum brevis muscle and its innervating lateral popliteal nerve is particularly advantageous. The legs are usually more affected than the arms in diabetic neuropathy, and the longest nerve fibres in the legs show the greatest reduction of conduction velocity (Lamontagne and Buchthal, 1970). The latter authors also found that slowing of the motor conduction in the lateral popliteal nerve was the one single measurement that correlated with the clinical severity of diabetes.

While we have not been primarily motivated in this study to examine the relationships between electrophysiological parameters and age of
Table 3 Correlations referred to in text: patients with diabetes mellitus

\begin{tabular}{llll}
\hline & & $r$ & P \\
\hline Age & Motor unit number & -0.500 & $<0.005$ \\
Duration of diabetes & Log (motor unit number) & -0.352 & $<0.05$ \\
Duration of diabetes & FMNCV & -0.439 & $<0.01$ \\
SDML & FMNCV & -0.455 & $<0.005$ \\
SDML & Motor unit number & -0.590 & $<0.001$ \\
FMNCV & Motor unit number & +0.564 & $<0.001$ \\
Mean MUP duration & SDML & +0.616 & $<0.001$ \\
Mean MUP duration & FMNCV & -0.528 & $<0.002$ \\
Mean MUP duration & Motor unit number & -0.543 & $<0.002$ \\
Mean MUP amplitude & Motor unit number & -0.386 & $<0.05$ \\
Mean MUP area & SDML & +0.407 & $<0.02$ \\
Mean MUP area & Motor unit number & -0.459 & $<0.01$ \\
Mean MUP latency & Mean MUP duration & +0.533 & $<0.002$
\end{tabular}

SDML $=$ shortest distal motor latency.

FMNCV = fastest motor nerve conduction velocity. MUP $=$ motor unit potential.

patients, duration of diabetes, and so forth, it is nevertheless pertinent to report such associations as we have found. We have confirmed the observation of Gregersen (1967) that in the normal population fastest motor nerve conduction velocity decreases with age in the lateral popliteal nerve ( $\mathrm{r}=-0.522 ; \mathrm{P}<0.05$, our study) although this is not the case in diabetic subjects. Gregersen (1967) attributed this lack of correlation to the presence of more marked slowing of conduction velocity in younger diabetic patients, thus masking the normal slowing that occurs with age. Our results would also be in agreement with that statement. The mean fastest motor nerve conduction velocity in patients below the age of 50 years is equal to that in patients above the age of 50 years $(42.3 \pm 5.8$ and $42.1 \pm 7.0 \mathrm{~m} / \mathrm{s}$, respectively, indicating that the slowing of conduction is relatively more marked in the younger of these two age groups. We have also found a significant negative correlation between the duration of diabetes, irrespective of age of onset, and the fastest motor nerve conduction velocities. In addition, there is a significant negative correlation between duration of diabetes and the logarithm of motor unit numbers. There is, however, no relationship between the duration of diabetes and motor unit potential parameters (vide infra).

The age of the patients at the onset of diabetes is not important in determining the presence or absence of neuropathy. While the duration of diabetes in the symptomatic group was longer than in the asymptomatic group, the difference was not statistically significant. When, however, we examined the whole group of diabetics, the relationships between fastest motor nerve conduction velocities, motor unit numbers, and duration of 
diabetes indicated that the risk of developing diabetic neuropathy increased with time. While no attempt was made in the study to grade the clinical severity or efficiency of control of diabetes, it is perhaps worthy of note that $75 \%$ of the symptomatic patients in the study were receiving treatment with insulin, while only $36 \%$ of the asymptomatic patients were on similar therapy.

\section{MOTOR UNI'T POTENTIAL LATENCIES}

The latency of the motor unit potential (MUP) is measured to the initial deflection of the potential on a computer printout (Ballantyne and Hansen, 1974b). This latency is the time taken for a nerve impulse generated in the anterior tibial nerve at the ankle to traverse the motor axon to its point of branching in the EDB muscle, plus the time for conduction over the shortest intramuscular branches of the parent axon and the delay at the neuromuscular junction. The mean latency of these motor unit potentials was significantly increased in the diabetic group as a whole and in the two subgroups of diabetic patients. The MUP latencies were greatest in those patients who had the most marked slowing of FMNCVs and the greatest prolongation of SDMLs (Tables 1 and 2). These are the patients with conventional electrophysiological signs of neuropathy. On the assumption (see later) that a preferential loss of fast-conducting motor axons has not occurred, those motor axons which have a reduced conduction velocity are likely to have a similar alteration of conduction velocity in their distal branches. This is supported by the significant negative correlation between shortest distal motor latencies and fastest motor nerve conduction velocities. Slowing of conduction in the intramuscular nerve fibres may also be due to intrinsically slow impulse propagation in immature collateral sprouts involved in reinnervation (Desmedt and Borenstein, 1976; Stålberg, 1976). Since only the shortest intramuscular nerve twigs of the motor unit contribute to the MUP latency, it is unlikely that slow conduction in immature sprouts produces a significant effect on MUP latency but it may be more relevant to the prolongation of MUP duration.

\section{MOTOR UNIT POTENTIAL DURATIONS}

As recorded from the relatively large surface electrode, MUP duration is determined by the differences in conduction time through the intramuscular nerve network of the motor axon, the conduction velocities of the action potentials of the muscle fibres of the unit, the absolute lengths of the muscle fibres, and the degree of dispersion of their endplates around the recording electrode (Ballantyne and Hansen, 1974b). Since there is no evidence to the contrary we have assumed that the electrophysiological properties of the muscle fibres in diabetic patients are similar to those of control subjects. That the prolonged durations of the motor unit potentials in the diabetic patients are due, at least in part, to reduction of motor nerve conduction velocity is supported by the demonstration of a significant negative correlation between FMNCVs and mean MUP durations, and a significant positive correlation between mean MUP latencies and durations (Ballantyne and Hansen, $1975,1976)$. The slowing of conduction velocity in the intramuscular nerve fibres produces an accentuation of the differences in conduction time over those fibres, a reduction in the temporal synchronisation of the responses of the muscle fibre action potentials with a consequent prolongation of the duration of the motor unit potential (Ballantyne and Hansen, 1974b). It is, however, possible in denervating diseases of muscle that there are other influences which tend to reduce the duration of the MUP. A 'dying back' type of degeneration of the longest intramuscular branches of the motor axon would reduce the absolute length differences between the remaining shortest and longest branches with a reduction in the differences in conduction time therein and resultant shortening of the duration of the MUP. The balance between these opposing influences (slowing of conduction in the intramuscular nerve fibre and loss of the longest intramuscular nerve branches) will determine whether the MUP duration is decreased, normal, or increased. This hypothesis will be elaborated in a later communication.

The negative correlation between MUP duration and FMNCVs raises the question as to whether the increase in the mean durations of motor unit potentials is due to a selective loss of motor units with action potentials of short duration and innervated by faster conducting axons? In our control subjects there was no correlation between MUP durations and FMNCVs or MUP latencies. In healthy subjects the fastest conducting motor axons do not necessarily give rise to motor unit potentials of short duration. In that circumstance it is unlikely that a selective loss of faster conducting axons alone can account for our results in patients with diabetic neuropathy. Rather the slowing of motor conduction velocities and the proportionate increase in MUP durations in these patients are both manifestations of a widespread impairment of function in motor nerve fibres. 
MO'TOR UNIT POTENTIAL AMPLITUDES

There was a significant increase in MUP amplitudes in symptomatic and asymptomatic patients which was, however, more marked in the asymptomatic group (Table 2). If the electrophysiological properties of the innervated muscle fibres in these patients remain normal, the greater amplitude of the MUP must reflect the presence of an increased number of muscle fibres with closely synchronised responses in the motor unit. Since the increase in mean MUP amplitude was positively correlated with an increase in mean MUP area the amplitude changes were not the result of internal remodelling of the motor unit but were due to the acquisition of additional muscle fibres from the overlapping territories of motor units that had become denervated. These high amplitude potentials indicate the presence of collateral reinnervation. The smaller increase in the mean MUP amplitude in the symptomatic patients (Table 2) was not due to a relatively reduced muscle fibre content of their units compared to the asymptomatic group as their mean MUP areas are comparable. It was a secondary effect of the increased duration of the motor unit potentials in these patients (Table 2).

\section{MOTOR UNIT POTENTIAL AREAS}

The increase in mean areas of MUPs in both the symptomatic and asymptomatic patients (Table 2) is indicative of an increased muscle fibre mass within the remaining motor units, and is further evidence of the acquisition and collateral reinnervation of muscle fibres from units that have become denervated. The overall increase in motor unit muscle fibre content was sufficient in the asymptomatic patients to compensate completely for reduction in motor unit numbers, and presumably prevented the occurrence of clinical weakness. Furthermore, the mean areas of the supramaximally evoked muscle action potentials from the EDB muscles in these patients were similar to those of control subjects-that is, the muscle fibre mass of the EDB muscles was comparable to that of healthy subjects despite the significant reduction in motor unit numbers in the former. In the symptomatic patients the capacity for further increase in muscle fibre content of motor units did not match the increased loss of motor units, and the total muscle fibre mass of the EDB muscle was reduced, a conclusion that was confirmed by a significant reduction in the area of the supramaximally evoked muscle action potential from the EDB muscles of these patients compared with control subjects $(P<0.01)$. That the absence of a further increase in motor unit muscle fibre mass is related to the underlying pathophysiological lesion in diabetic neuropathy and not to normal physiological factors which limit motor unit size is illustrated by the much larger MUP areas that we have found in patients with motor neurone disease (Ballantyne and Hansen, in preparation).

Simple demyelination and demyelinative conduction block are not associated with anatomical denervation of muscle fibres (Adams et al., 1962; Gilliatt, 1973), and electrophysiological evidence in the form of fibrillation potentials is not found (Robert and Oester, 1970). The changes we have found in MUP parameters are, therefore, the result of axonal dysfunction which is marked in patients with and without neuropathy.

The principal pathological lesion in diabetic neuropathy is segmental demyelination and remyelination (Thomas and Lascelles, 1966; Chopra et al., 1969) although some evidence of axonal degeneration can be found in severe or chronic cases (Chopra et al., 1969). However, in mild and less severe cases the predominant abnormality is segmental demyelination (Gilliatt, 1973). Axonal loss was noted by Dolman (1963) who also found evidence of neurogenic atrophy in muscle biopsies in some $30 \%$ of cases. Electrophysiological changes in the form of fibrillation potentials (Mulder et al., 1961; Lamontagne and Buchthal, 1970) and reduction in the interference pattern on voluntary effort would indicate that a degree of axonal dysfunction is present in diabetic neuropathy, and while Brown and Feasby (1974) noted a reduction in motor unit numbers in their study, none of these authors were able to quantify the axonal dysfunction. Since axonal degeneration does not figure prominently in nerve biopsy material from diabetic patients we have avoided the use of this term in discussing our results. Axonal degeneration is a histological diagnosis based on the presence of structural abnormalities in the axon or the disappearance of axons in the pathological material. Our electrophysiological evidence of severe axonal dysfunction in diabetes mellitus would indicate the limitations of conventional histological techniques in the presence of disturbances of axonal function.

It is well established that demyelinative neuropathies are associated with marked slowing of conduction velocity (McDonald, 1962, 1963; Cragg and Thomas, 1964; Lehmann, 1973). These investigations have largely involved the correlation of conduction velocities with histopathological evidence of demyelination. It will, however, be apparent from our results that conduction velocity 
studies alone will give little indication of the presence or severity of a concomitant axonal disturbance which, in the case of motor axons, is revealed by the quantitation of the induced pathophysiological changes in the muscle. Many of the investigations of segmental demyelination involve acute lesions in previously healthy nerve fibres, and these have shown a capacity for rapid remyelination and the re-establishment of normal conduction velocities (Gilliatt, 1973). Significant axonal dysfunction may be absent in these cases, and indeed, in the more acute demyelinating neuropathy associated with the Guillain-Barré syndrome, we have found evidence of an axonal dysfunction (Martinez-Figueroa et al., 1977) but this is less severe than in our patients with diabetic neuropathy. Gilliatt (1973) stated that 'repeated cycles of myelin breakdown and repair produce effects on conduction velocity' [and presumably other parameters] 'very different from those seen in a single demyelinative episode produced in the experimental animal'.

In the group of diabetic patients as a whole, mean motor unit potential durations have a significant positive correlation with shortest distal motor latencies. Mean motor unit potential amplitudes and mean motor unit potential areas each show a significant positive correlation with shortest distal motor latencies. In addition, mean motor unit potential durations, amplitudes, and areas individually have a significant negative correlation with motor unit numbers. The relationship that these correlations indicate can be summarised as follows: as the number of motor units in the EDB muscle falls there is a progressive increase in the durations, amplitudes, and areas of the potentials of viable motor units. In other words, the progressive reduction in motor unit numbers is accompanied by a progressive and proportionate increase in the amount of collateral reinnervation. It is a necessary corollary of this statement that the severity and extent of muscle fibre denervation is also in proportion to the reduction in motor unit numbers. The severity of axonal dysfunction is, therefore, in proportion to the reduction in motor unit numbers. We have, however, noted a strong positive correlation between motor unit numbers and fastest motor nerve conduction velocities, and a significant negative correlation with shortest distal motor latencies (Figs. 1 and 2) and, since it is well established that the slowing of conduction velocity in demyelinative neuropathies is an index of the severity and extent of that demyelination, we can modify our conclusions as follows: as the severity of demyelination increases there is a pro- gressive and proportionate reduction in motor conduction velocity, a corresponding fall in motor unit numbers and a progressive and proportionate increase in the amount of muscle fibre denervation and collateral reinnervation.

Axonal dysfunction is a prominent and integral part of the neuropathy of diabetes mellitus. It is present in proportion to and parallels the severity of the demyelinative lesion in that condition. The efficiency of the collateral reinnervation which accompanies the axonal dysfunction is such as to mask the clinical signs of motor neuropathy in the milder cases.

This work was supported by a grant from the Wellcome Trust $(\mathrm{SH})$. We would like to thank Professor J. A. Simpson for his help and encouragement, Dr S. Slater who referred many of the patients, and Miss E. Robb for secretarial assistance.

\section{References}

Adams, R. D., Denny-Brown, D.. and Pearson, C. M. (1962). Diseases of Muscle. A Study in Pathology, 2nd edition. Harper: New York.

Ballantyne, J. P., and Hansen, S. (1974a). A new method for the estimation of the number of motor units in a muscle. 1. Control subjects and patients with myasthenia gravis. Journal of Neurology, Neurosurgery, and Psychiatry. 37, 907-915.

Ballantyne. J. P., and Hansen, S. (1974b). Computer method for the analysis of evoked motor unit potentials. 1. Control subjects and patients with myasthenia gravis. Journal of Neurology, Neurosurgery, and Psychiatry, 37, 1187-1194.

Ballantyne, J. P., and Hansen, S. (1975). Computer method for the analysis of evoked motor unit potentials. 2. Duchenne, limb-girdle, facioscapulohumeral and myotonic muscular dystrophies. Journal of Neurology. Neurosurgery, and Psychiatry, 38, 417-428.

Ballantyne, J. P.. and Hansen. S. (1976). Further electrophysiological evidence for a neurogenic influence on the muscular dystrophies. In Fifth International Scientific Conference sponsored by the Muscular Dystrophy Association. 21-25 June 1976. Tamarron. Durango, Colorado.

Brown, W. F., and Feasby, T. E. (1974). Estimates of functional motor axon loss in diabetes. Journal of the Neurological Sciences, 23, 275-293.

Chopra. J. S., Hurwitz, L. J., and Montgomery, D. A. D. (1969). The pathogenesis of sural nerve changes in diabetes mellitus. Brain, 92, 391-418.

Cragg, B. G., and Thomas, P. K. (1964). Changes in nerve conduction in experimental allergic neuritis. Journal of Neurology. Neurosurgery, and Psychiatry, 27, 106-115.

Desmedt, J. E., and Borenstein, S. (1976). Regenera- 
tion in Duchenne muscular dystrophy. Archives of Neurology (Chicago), 33, 642-650.

Dolman, C. L. (1963). The morbid anatomy of diabetic neuropathy. Neurology (Minneapolis), 13, 135142.

Gilliatt, R. W. (1973). Recent advances in the pathophysiology of nerve conduction. In New Developments in Electromyography and Clinical Neurophysiology, Vol. 1, pp. 2-18. Edited by J. E. Desmedt. Karger: Basel.

Gilliatt, R. W., Goodman, H. V., and Willison, R. G. (1961). The recording of lateral popliteal nerve action potentials in man. Journal of Neurology, Neurosurgery, and Psychiatry, 24, 305-318.

Gilliatt, R. W., and Willison, R. G. (1962). Peripheral nerve conduction in diabetic neuropathy. Journal of Neurology, Neurosurgery, and Psychiatry, 25, 11-18.

Gregersen, G. (1967). Diabetic neuropathy: Influence of age, sex, metabolic control and duration of diabetes on motor conduction velocity. Neurology (Minneapolis), 17, 972-980.

Lamontagne, A., and Buchthal, F. (1970). Electrophysiclogical studies in diabetic neuropathy. Journal of Neurology, Neurosurgery, and Psychiatry, 33, 442-452.

Lehmann, H. J. (1973). Segmental demyelination and changes in nerve conduction in experimental circumscribed neuropathy. In New Developments in Electromyography and Clinical Neurophysiology, Vol. 1, pp. 145-157. Edited by J. E. Desmedt. Karger: Basel.
McDonald, W. I. (1962). Conduction in muscle afferent fibres during experimental demyelination in cat nerve. Acta Neuropathologica, 1, 425-432.

McDonald, W. I. (1963). The effects of experimental demyelination on conduction in peripheral nerve. II. Electrophysiological observations. Brain, 86, 501524.

Martinez-Figueroa, A., Hansen, S., and Ballantyne, J. P. (1977). A quantitative electrophysiolcgical study of acute idicpathic polyneuritis. Journal of Neurology, Neurosurgery, and Psychiatry, 40, 156161.

Mulder, D. W., Lambert, E. H., Bastron, J. A., and Sprague, R. G. (1961). The neuropathic association with diabetes mellitus. A clinical and electromyographic study of 103 unselected diabatic patients. Neurology (Minneapolis), 11, 275-284.

Rcbert, E. D., and Oester, Y. T. (1970). Nerve impulses and trophic effect. Absence of fibrillation after prolenged and reversible conduction block. Archives of Neurology (Chicago), 22, 57-63.

Stålberg, E. (1976). Electrogenesis in dystrophic human muscle. In Fifth International Scientific Conference sponsored by the Muscular Dystrophy Association. 21-25 June 1976. Tamarron, Durango, Colorado.

Thomas, P. K., and Lascelles, R. G. (1966). The pathology of diabetic neuropathy. Quarterly Journal of Medicine, 35, 489-509. 